\title{
HARRISON BRYAN
}

\section{A View of Libraries Down Under}

Editor's Note: We are pleased to supplement Harrison Bryan's article with these photographs of Australian university libraries selected by the author and with his captions. We record our thanks to the universities and the libraries represented here for their helpfulness in supplying these photographs.

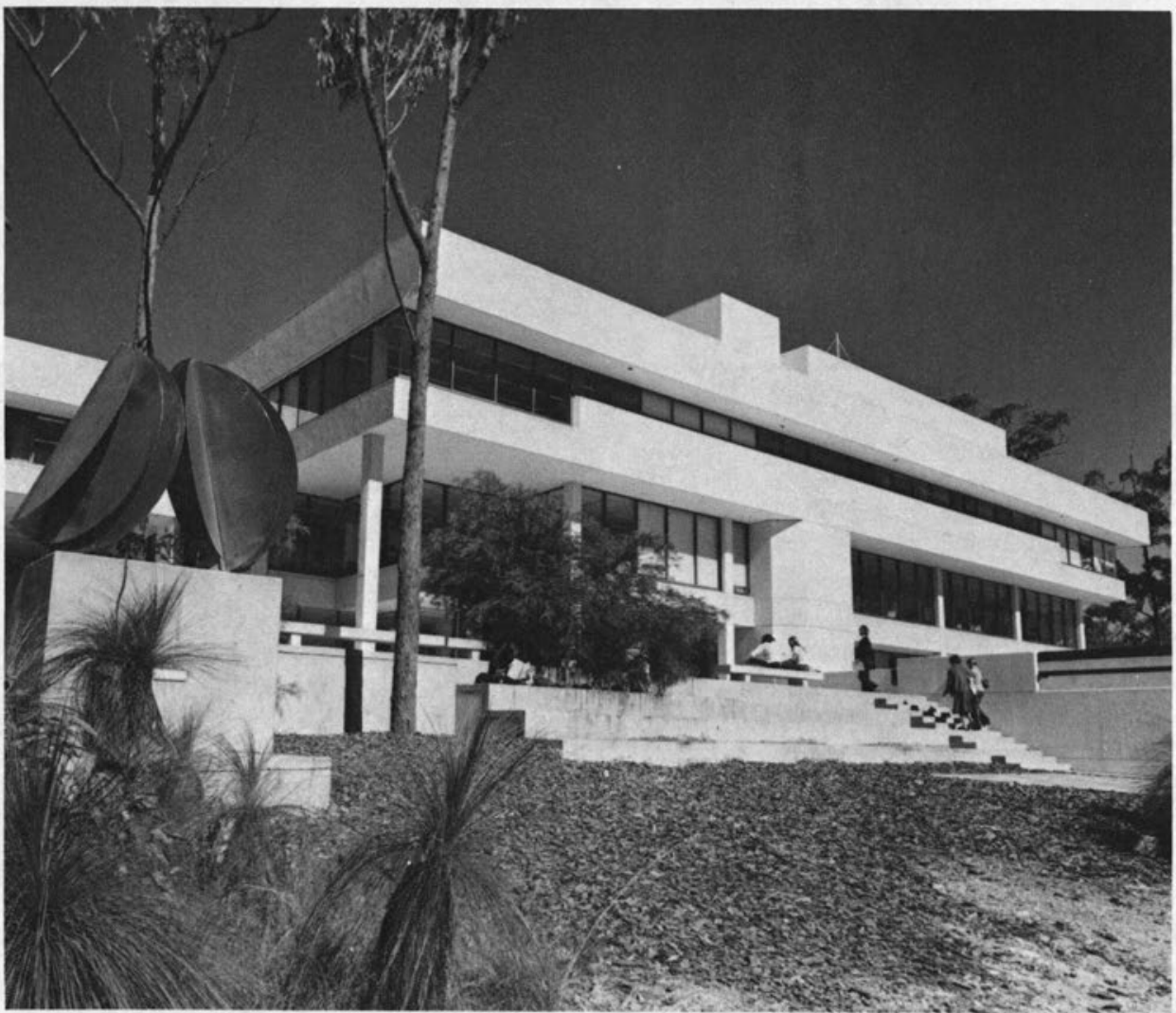

Griffith University Library. Designed for Brisbane's subtropical climate, this is among the most recent of the academic library buildings in the country. The campus has retained much of its bush setting. 


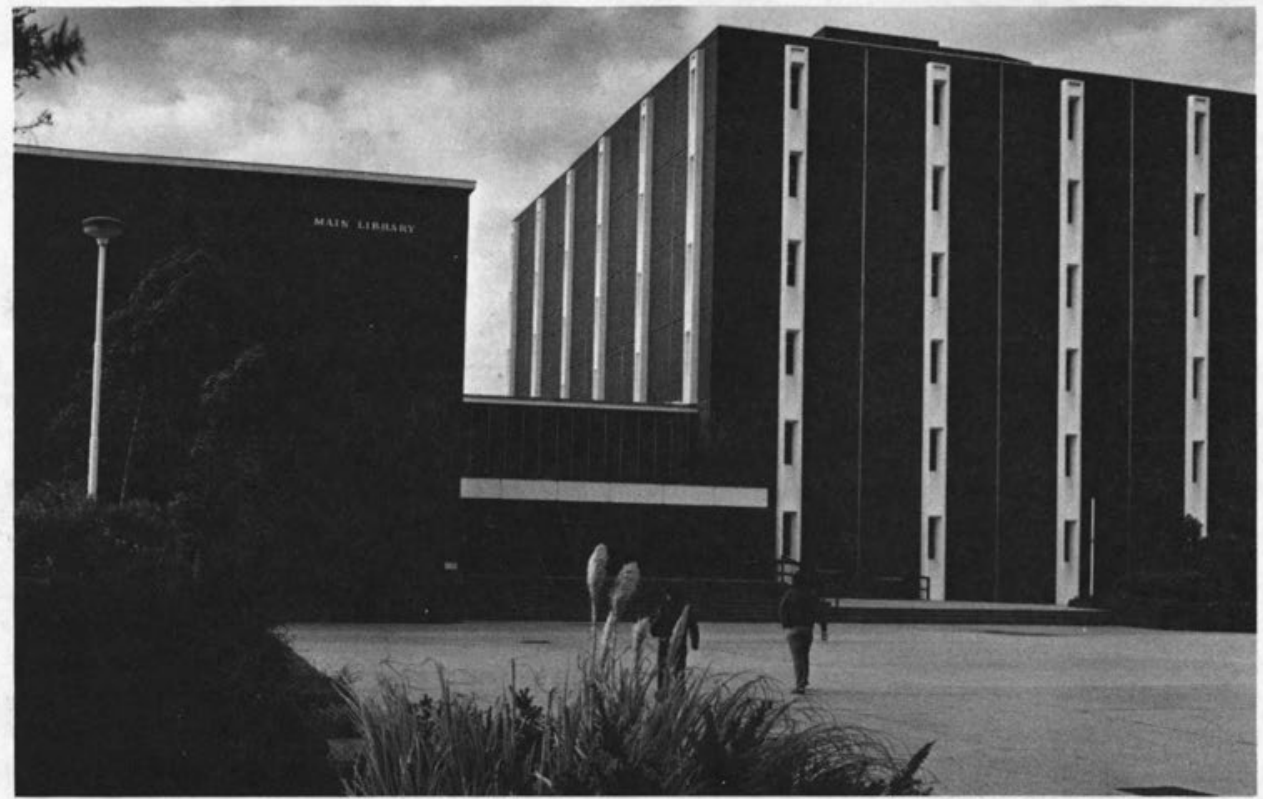

Monash University Main Library. This building, erected in three stages, 1964-1974, has accommodation for 816,000 volumes and 2,113 readers. It is complemented by three separate and reasonably adjacent buildings housing collections and services respectively in law, biomedical sciences, and applied sciences and engineering.

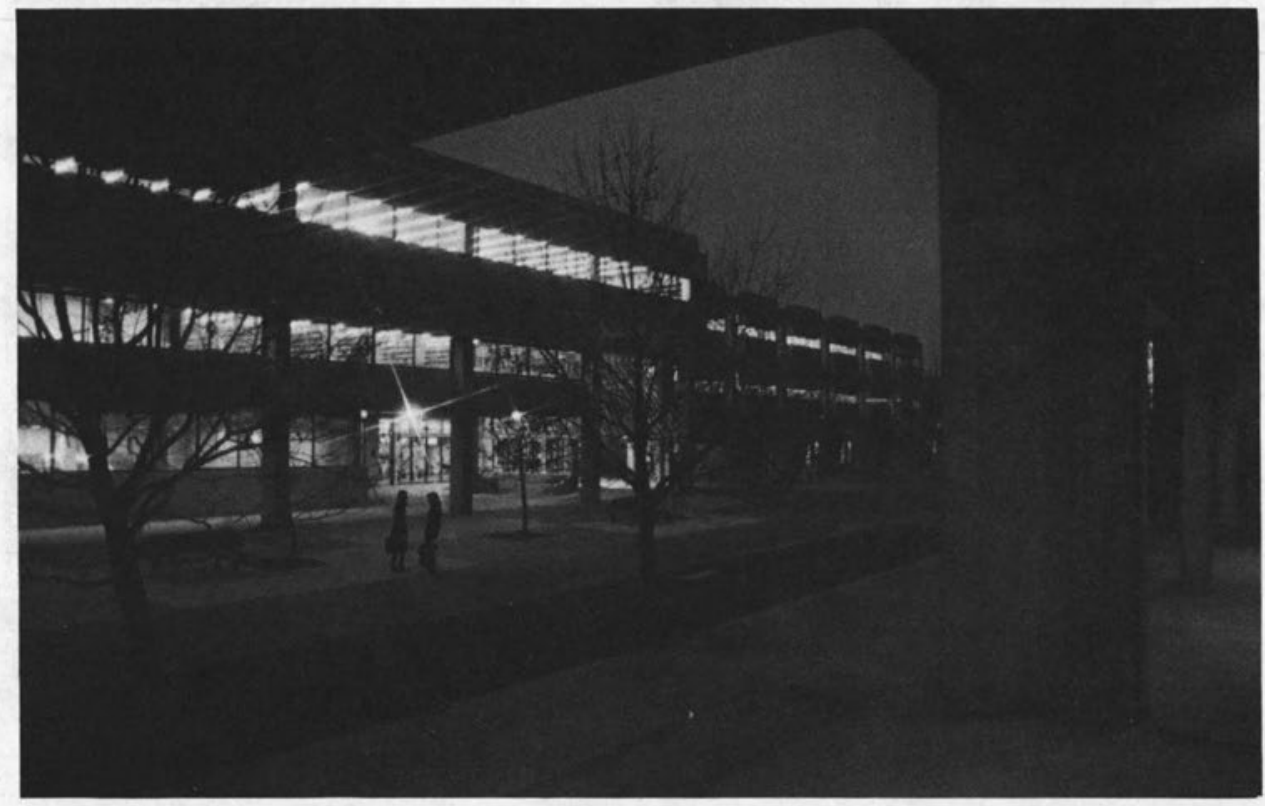

Macquarie University Library. The building was erected in four stages, 1966-1978, to serve the third university in Sydney. It was designed and built by the New South Wales state government architect. 


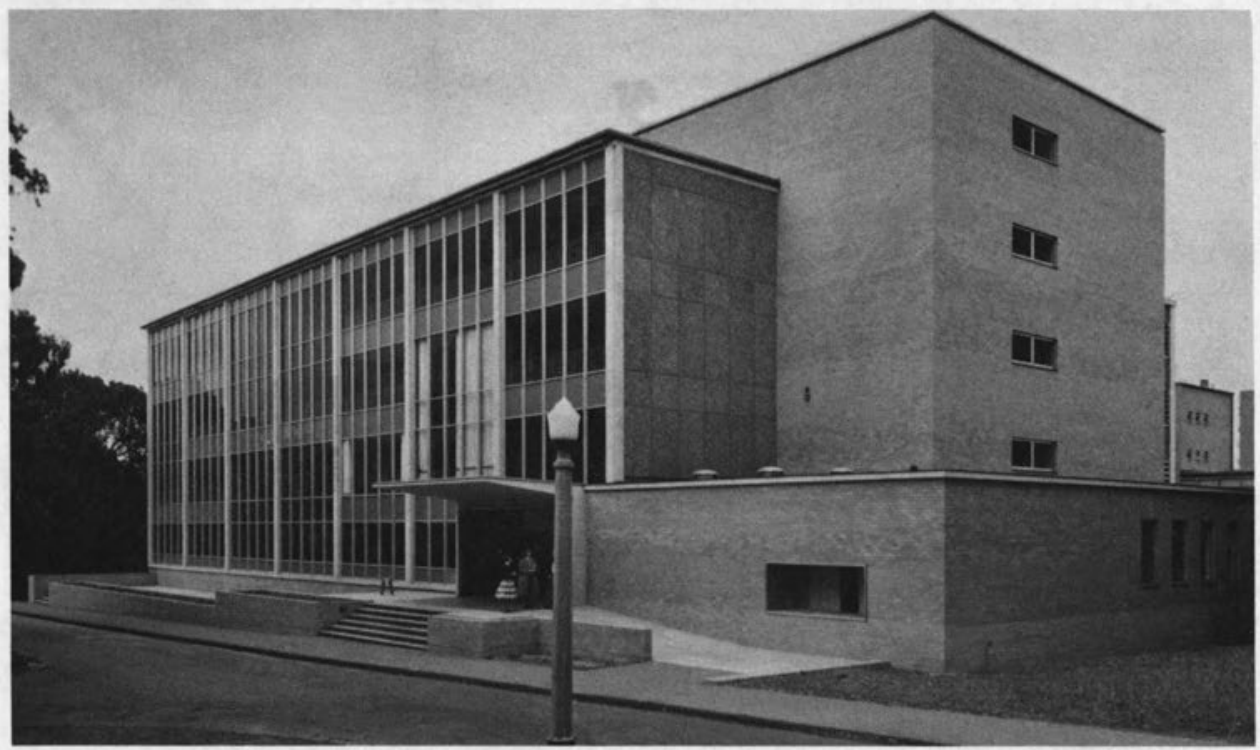

Baillieu Library, University of Melbourne. This historic picture records the completion, in 1959, of the first stage of the first of the custom-designed Australian academic libraries. Later extensions have brought the total gross area to 20,438 square meters.

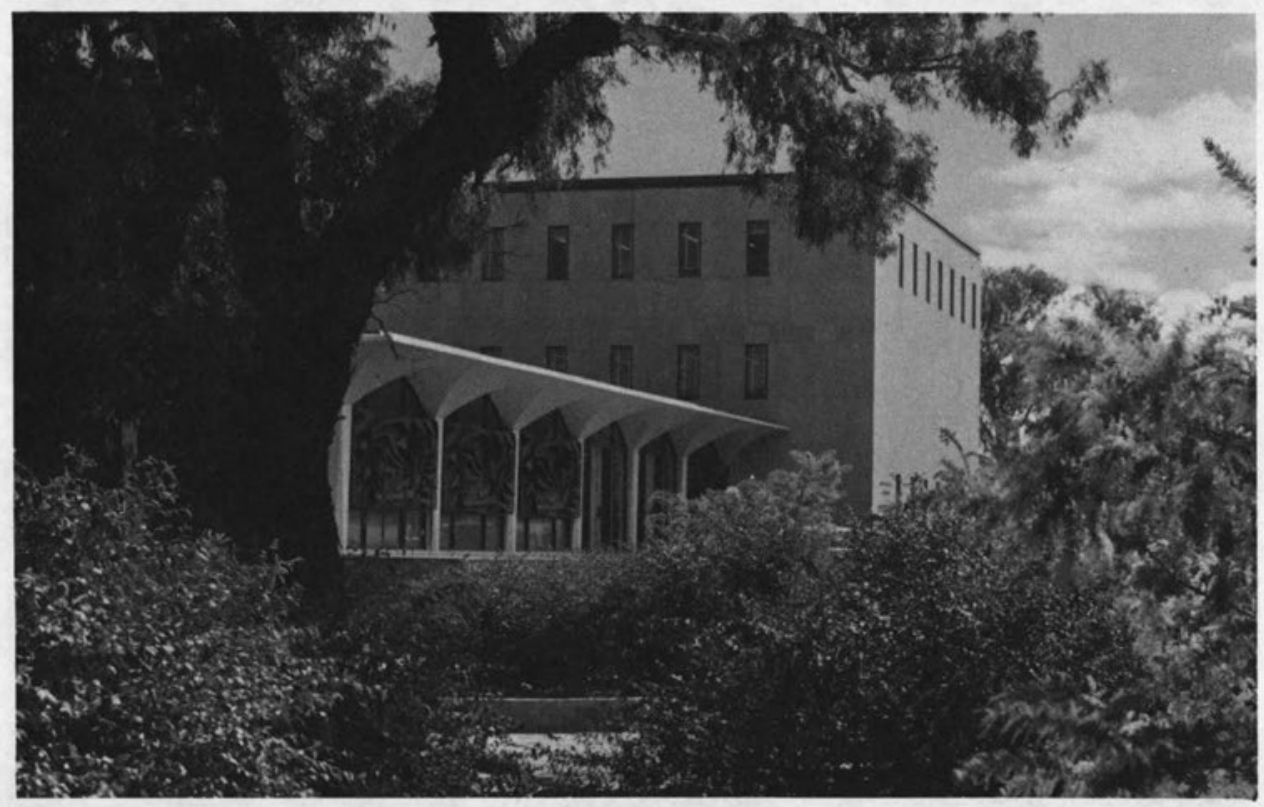

Menzies Library, Australian National University. Designed to serve originally the completely research-dedicated ANU, the Menzies Library demonstrates rather more conscious concern for outward appearances than do most Australian academic libraries. Completed in 1963, it grosses 7,432 square meters. 


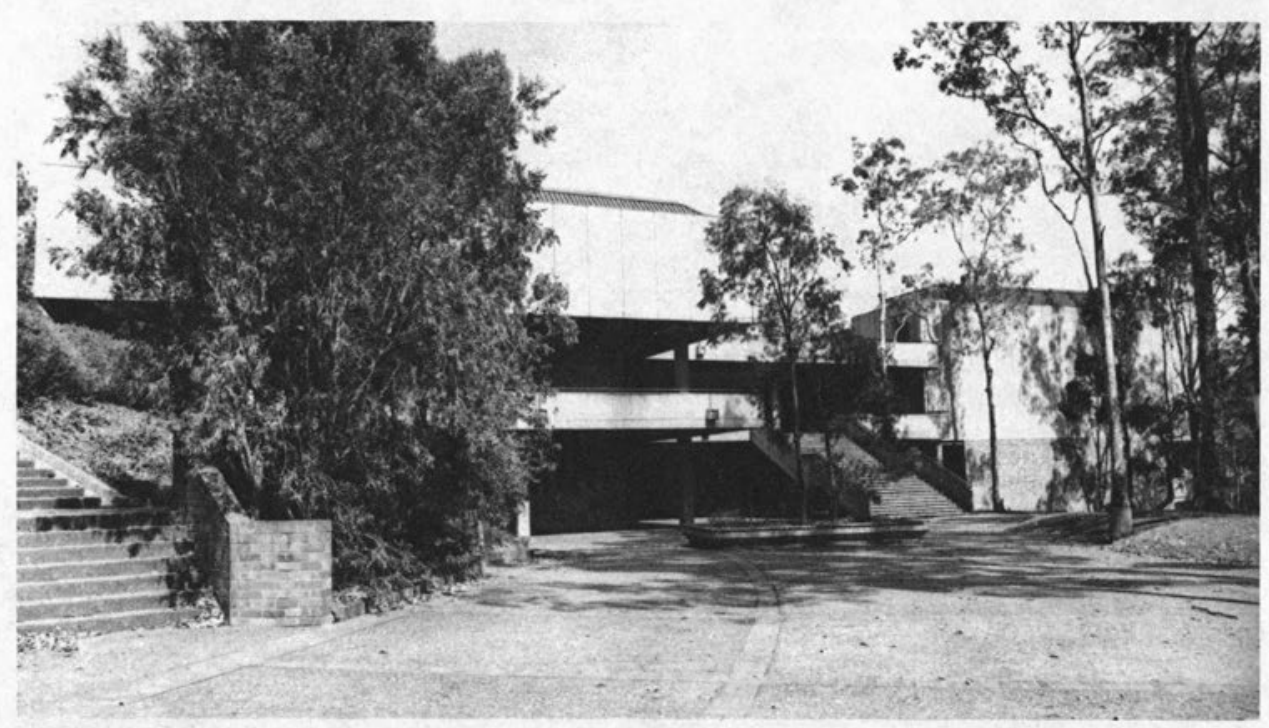

Auchmuty Library, University of Newcastle. The first two stages of a planned three-stage building, this library houses 300,000 volumes and 1,000 readers. Campus planners have made a conscious effort to retain the Australian eucalyptuses that clothe the site.

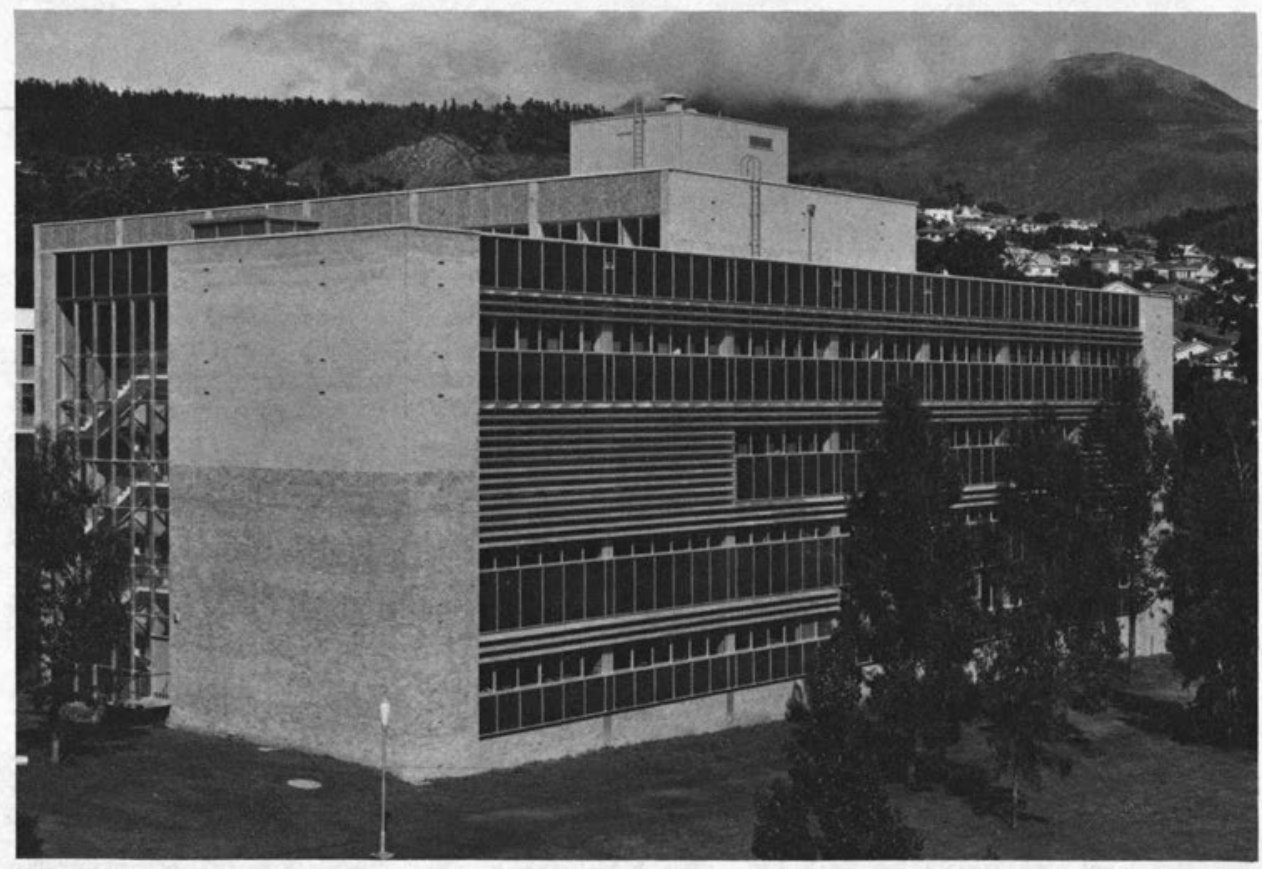

Morris Miller Library. Designed by the same architect as the Baillieu Library, University of Melbourne, this, the University of Tasmania's central library building, was completed in two stages, 1959-1969. It accommodates 236,500 volumes and 650 readers. 


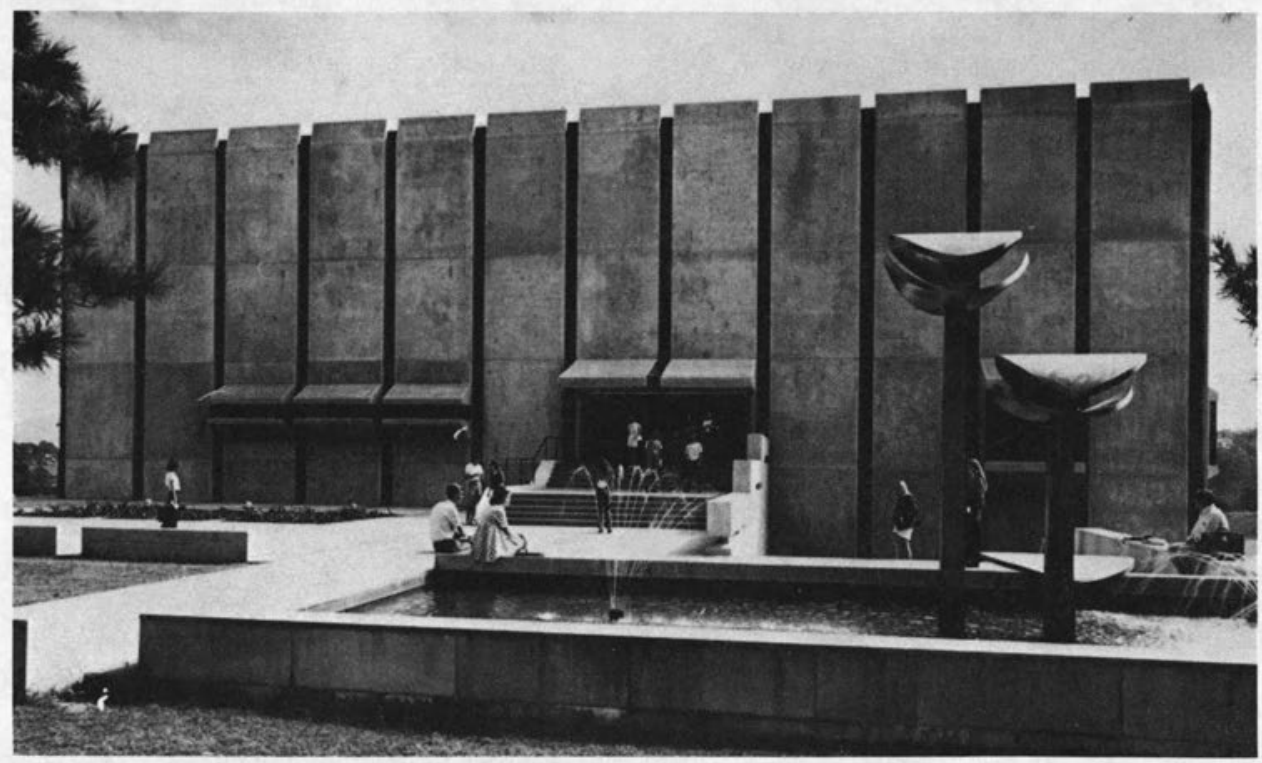

University of Queensland Central Library. This first stage houses 500,000 books and seats 390 readers. The building is designed for an ultimate quadruplication of these provisions. There is a separate undergraduate library building immediately adjacent.

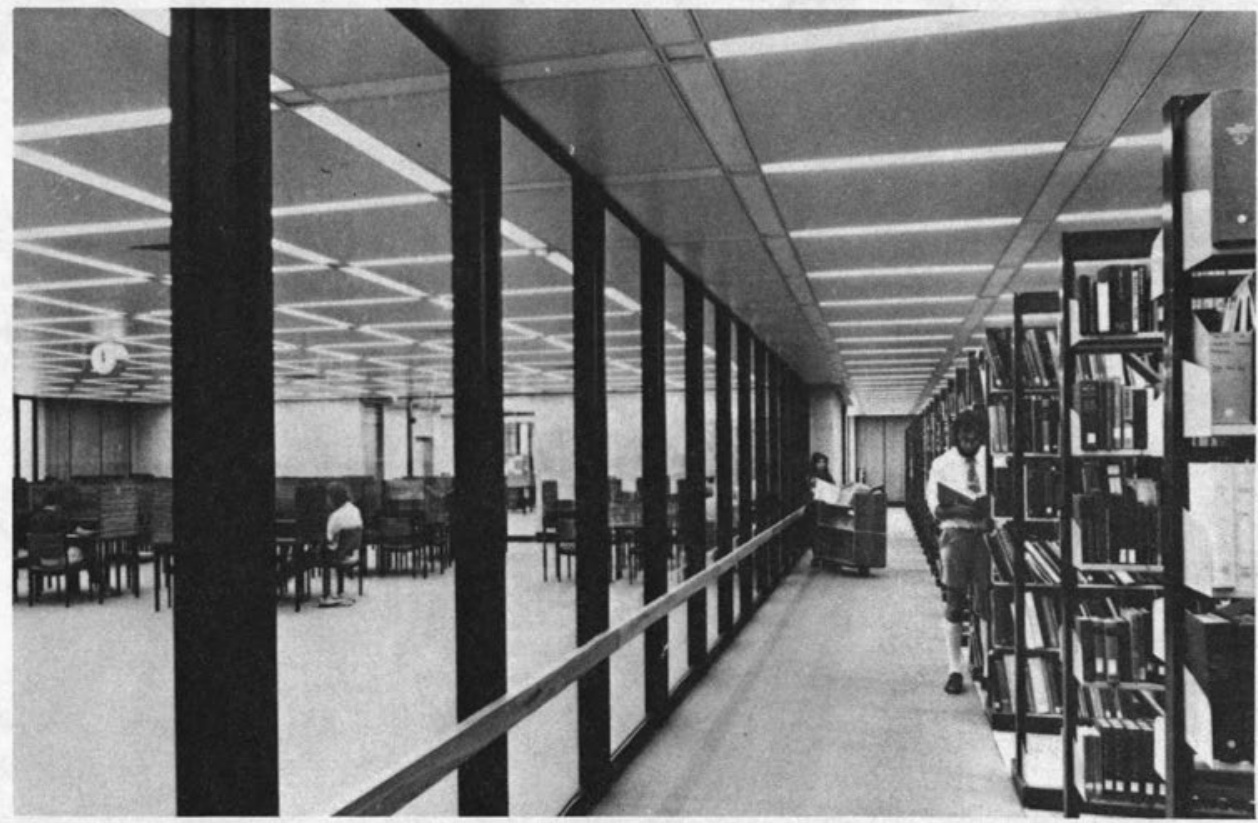

University of Queensland Central Library. The photograph illustrates the physical separation but visual integration of stack and reading areas. This is the only example in Australia of a controlled access collection. 


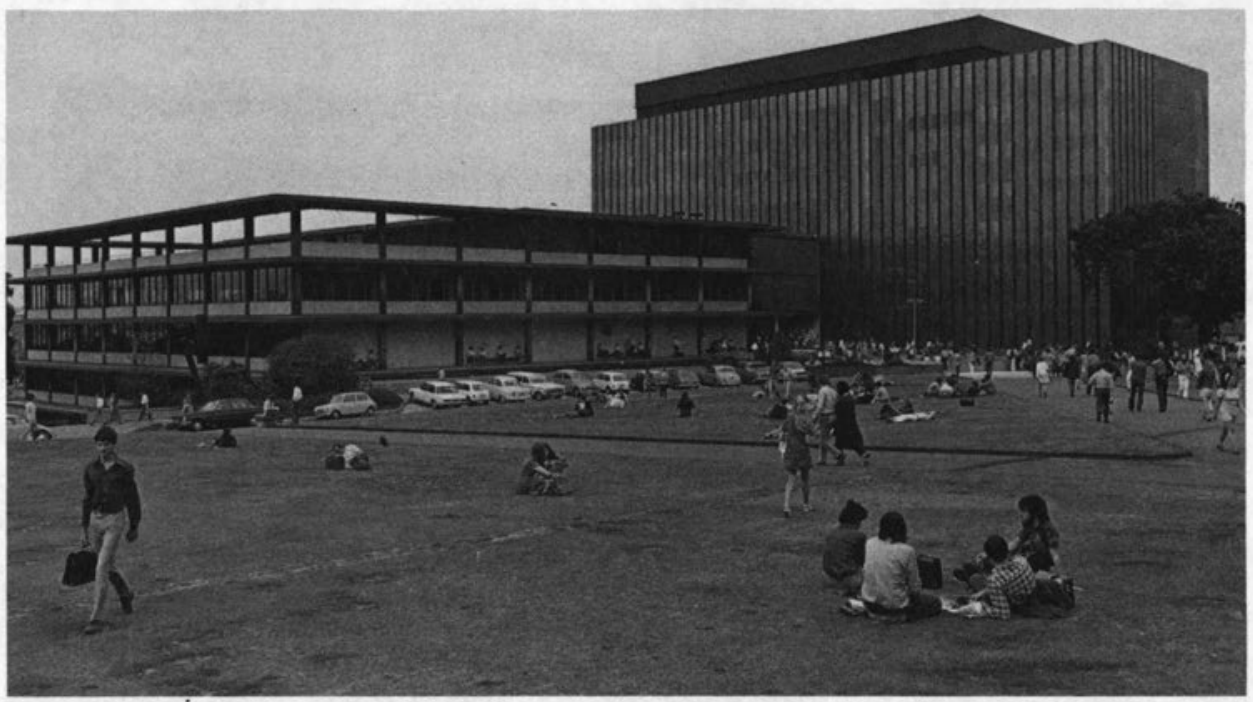

Fisher Library, University of Sydney. Designed by T. E. O'Mahoney and the state government architect of N.S.W., Fisher, Australia's largest and heaviest used academic library building, was erected in two stages, 1963-1971. It grosses 23,225 square meters and provides space for 3,100 readers and three million volumes.

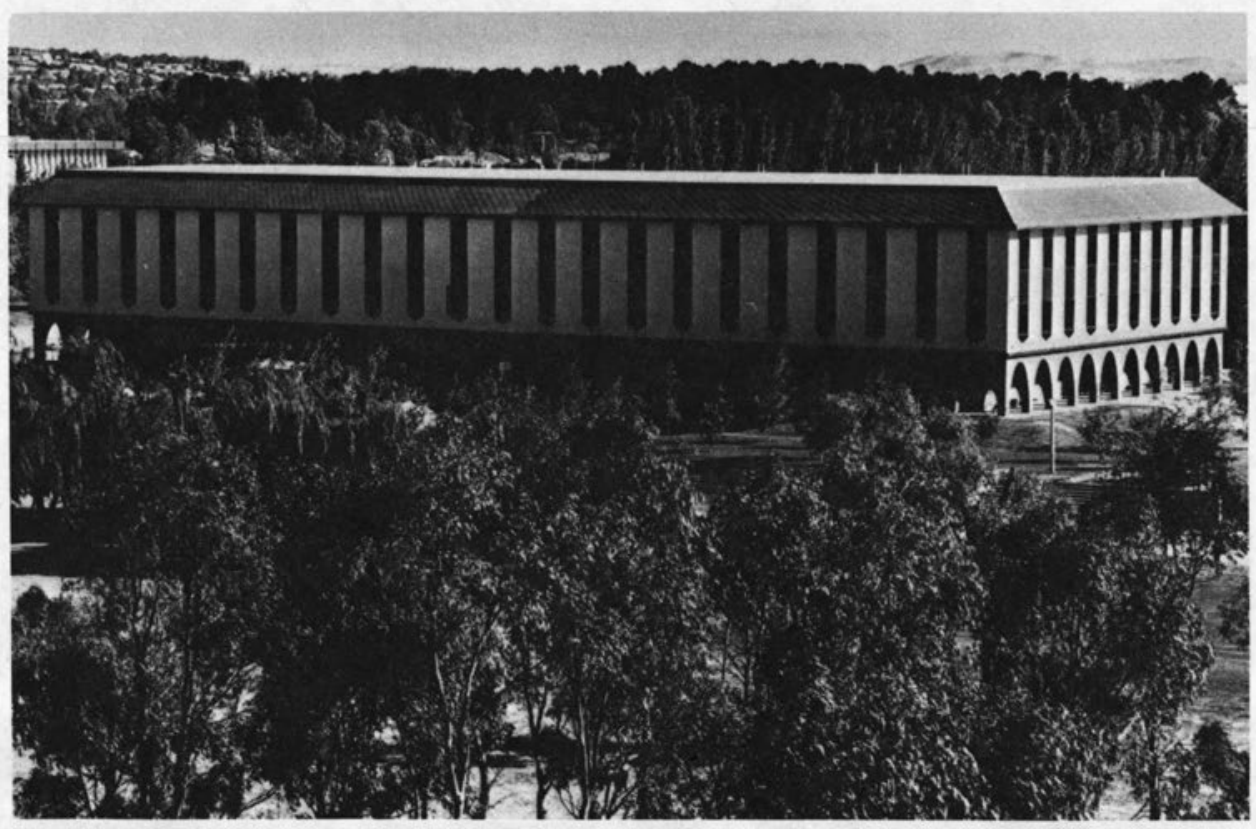

Chifley Library, Australian National University. Designed originally as the library of Canberra University College, the Chifley building was developed largely to house undergraduate services for the amalgamated university. Its capacity is 250,000 volumes and 1,300 readers. 